\title{
The Study of PBL at K12 Education and the Higher Education
}

\author{
Hao $\mathrm{Ni}^{1, *, \dagger}$, Ziyu Wan ${ }^{2, \dagger}$, Siting Yang ${ }^{3, \dagger}$ \\ ${ }^{1}$ School of Huangshan University, Huangshan,245021, Anhui, China \\ ${ }^{2}$ School of Qingdao University of Technological, Qingdao, Shandong ,266525, China \\ ${ }^{3}$ School of Chongqing Normal University, Chongqing 40070, China

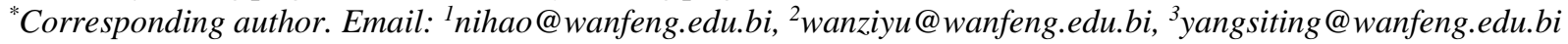 \\ Those authors contributed equally.
}

\begin{abstract}
Problem Based Learning(PBL), which uses teamwork study, is a learner-centered teaching model. This pattern can contribute to cultivating self-study ability and improving learning effects during the process of finding and solving problems. Though summarizing the present situation of using the PBL teaching method at different levels of education, the aim of this study is to provide new thinking for the education reform. Compared with the conventional teaching method, PBL has already become a breakthrough in the teaching models. PBL teaching pattern at K12 Education and the Higher Education levels of education is the main topics of the study. The main content of this article is a review about this teaching pattern. In this article, we will start with the background and design process of PBL. Then, we run an extended analysis of PBL used in different levels of education, including preschool education, primary education, and higher education. Previous research show that people behave differently at different ages. Also, the contents of learning are emphasized differently for students at various education stages. Therefore, the specific usage of the PBL teaching method is other in different levels of education. It is significant for improving the teaching to compare PBL and conventional teaching styles and learn from them according to the situations in teaching reform. In the section of the PBL teaching pattern used in different education stages, this paper points out that this review includes the application and evaluation of the PBL teaching model. Furthermore, each level of education has its concrete framework of implementation. Though the PBL teaching pattern can make students learn actively, it is still imperfect in some places. For example, in the concrete implementation process, teachers should improve PBL and build relevant model to the actual courses. With the continuous improvement of PBL teaching patterns, the application will be a broader prospect.
\end{abstract}

Keywords: PBL, The preschool education, The primary education, The higher education, Education, Education stage.

\section{INTRODUCTION}

PBL teaching method is significant in current education. It can improve students' initiatives in learning and enhance the participation of students in the learning process, which is conducive to active students' thinking. In the recent decade, it is widely used in the education of all ages with remarkable effects. In this context, this review paper focuses on applying PBL to current education, including preschool education, primary education, and higher education. This paper aims at the differences of PBL in three stages:
(1) In preschool education, we mainly investigate how students discover, explore and solve problems under the PBL teaching method.

(2) In primary education, we mainly explore the differences between the PBL teaching method and the traditional teaching method and evaluates the application of PBL in primary education.

(3) In higher education, we explore how teachers use PBL to make it play a better role.

This paper aims to analyze the application of PBL in three different educational stages in details. 


\section{PBL TEACHING PATTERN USAGE IN THE PRESCHOOL EDUCATION}

The traditional teaching method is based on the disciplinary knowledge, and it is basically to teachers' teaching as the center. But the PBL teaching pattern is different, PBL Learning situation of the teaching method is a design. Primarily through demonstrating the authentic problem, it stimulates the student to explore the desire through students' feelings and the team cooperation way to solve the problems and improve their ability to solve the issues and quality constantly.

\subsection{The Application of PBL Model in Preschool Education}

\subsubsection{Step1: Find problems}

Through problem setting or combining with the course content, students can find out their own weak links according to their basic situation, sort out the problems, and form the main body of Inquiry Summarize and sort out the main problems of the whole class. According to the self-examination results of the students, teachers and students discuss together to determine the order, key points and difficulties of the course learning content. While respecting the principal position of students, it improves the timeliness and pertinence of teaching and student's interests in learning [1].

\subsubsection{Step2: Explore the problem}

Through the interactions and cooperation of students to solve problems, teachers should implement dynamic management, timely grasp and understand the overall situation of the group to put forward the most appropriate help for children's learning. In group cooperation, children no longer passively accept or just be onlookers. They actively conceive, actively express, observe, listen to children's special words, and guide children to explore their own hearts by asking questions, and guide children to carry out group cooperation. Warnock and Mohammadi-Aragh mentioned in their paper that "Fortyseven students enrolled in a biomedical materials course participated in the case study [2]. Students worked in teams to complete a series of problems throughout the semester. The results showed that students made significant improvements in their problem-solving skills, written communication and self-directed learning. Students also demonstrated an ability to work in teams and communicate orally. In conclusion, this case study provides empirical evidence of the efficacy of PBL on student learning [2]."

\subsubsection{Step3: Solve the problem}

GTortorella and Cauchick-Miguel argue that "PBL may be an effective complementary method for LM learning, especially because it exposes students to actual problems when implementing LM. The proposal may improve problem-solving ability and provide a more fertile environment to promote better learning experience [3]." I would regard the same idea applies to preschool education. Teachers participate in each link of project learning as "participants and instructors", willing to "let it go." Therefore, children can independently explore, discover and practice. Explore activities in groups, record and produce results, display and communicate, constantly stimulate and consolidate children's sense of selfefficacy, and finally promote children's healthy growth.

\subsection{Key points in the Application of $P B L$ Teaching Mode in Preschool Stage}

\subsubsection{Combine the actual situation}

Children's cognitive thinking determine that virtual thing is more difficult to stimulate children's interest, cause emotional resonance. For children in different regions, education needs to be closer to life, drawing materials from real resources and based on children's life experience [4].

\subsubsection{Open and pluralistic thinking}

For preschool children, the acquisition of experience, divergent thinking, good learning habits and other developmental goals, is the key to carry out project learning. In practice, children should observe and find problems from multiple angles; Teachers look at young children with an open and developmental perspective.

\subsubsection{Appropriateness}

We should choose the most needed part of children's development rather than use new teaching methods to choose new learning methods. PBL teaching mode in kindergarten stage has certain conditions and scope. In combination with the existing resources of kindergartens, only by appropriately carrying out exploratory practice activities in the fields of science and health can they play their role more efficiently [4].

This is the application of PBL in preschool education. In addition, three points should be noted in primary education in the application of PBL.

\section{PBL TEACHING PATTERN USAGE IN THE PRIMARY EDUCATION}

\subsection{The Differences between Traditional Teaching Pattern and PBL Teaching Pattern}

Primary education is the start-up that a student accepts the initial stages of school education, and it plays a vital part in everyone's life. It is also the foundation of later 
learning. In the following study, the primary school developing a good learning habit will directly affect students' learning efficiency and quality, which many education experts have universally recognized about this. The primary role of the traditional educational pattern is the teacher who is to control students, that is, the teachercentered teaching model. In other words, as long as teachers have the right direction, specific goals, and detailed teaching thoughts will receive good education results. Therefore, there are many problems with traditional teaching pattern.

The first large problem, although this pattern improves teachers' effectiveness in the classroom, educators will excessively focus on knowledge retention, which will consume children's interests in the study and even put them off learning. In addition, students' learning will become rely on teachers' teaching, which will make students develop bad habits. The second problem, students still remain on the surface in understanding many knowledge. But teachers need to talk about the substance of the problem with students instead of staying on the surface. For students, they should deal properly with the question, instead of just picking at it. If they cannot acquire deep learning skills, they will become helpless when they have problems in their study. Also, studying on the surface is bad for students' future learning. The third problem, traditional teaching pattern is lack of interaction and practice. It is not good for interpersonal relationships. Therefore, some students cannot get along well with other people. With the deepening of educational reform, traditional teaching methods cannot adjust to the requirement of future social; thus, we should investigate new teaching methods that match the modern education thought. PBL teaching pattern provides many practical ways to traditional primary education. Compared with the standard teaching model, student-centered and problem-based are the most significant difference. PBL teaching pattern makes teacher' s role change.

\subsection{The Application of PBL in Classroom Settings}

Nowadays, PBL has been widely used in elementary school education. There are four steps in the design processes of PBL. Therefore, the first thing we should do is to determine learning goals. Second, scenario selection and framing research questions. Below is an example from Wei's research: one of the teacher participants raises a question: "opponents (i.e., students) always keep appearing in our lives, so they are friends (to teachers) or not [7]?" In this teaching pattern, problems present by teachers are closely related to real life, which will arise students' interest. We usually have no fixed answers for these problems, but everyone knows it is in his heart. Third, searching for learning materials independently and in group learning. In this part, students should experience an autonomic study process and gather substantial sources to understand these problems fully. During selflearning, students will get many new issues that need group learning to help them solve. In the course of group study, students listen to their fellow students' opinions and debate with them if there is a disagreement-lastly, learning outcomes report and evaluation. Teachers will organize a presentation about this project. Let children be the teacher, listen as they show what they know during this project. In addition, the form of expression should be various, including report, proposal, video, theme museum, and so forth.

\subsection{The Evaluation of PBL Teaching Pattern in Primary Education}

PBL teaching patterns can create studying situations or conduct situational teaching to help students actively learn, cooperate, explore, and complete knowledge. If teachers applied this method more extensively, these problems would be minimized, while both students and their teachers would benefit from it [8]. For students, the PBL model helps them achieve a high-order cognitive skill, including analysis, synthesis, and evaluation [9]. Group learning can improve students' social competence. As learning is not a solitary activity but requires collaboration among people, students of all ages will benefit academically if they frequently work in groups.

It is also beneficial to students' further study. Odell et al. refers that there were several challenges identified when implementing PBL throughout the evaluation process [10]. Aksela et al. refer that PBL is not likely to work unless projects are designed; with teacher support, they marshal, generate, and sustain student motivation and thoughtfulness [11]. Therefore, the PBL teaching pattern has some space for improvements. In the concrete implementation process, teachers should make an intensive study and practice of PBL teaching pattern in every single subject. Especially, teachers should try to build up a teaching method system of problem-based deep learning which is based on keeping summarizing and improving. And finally, we will constantly improve the quality of primary education and cultivate students' interpersonal communication skills, creative problem solving, independent thinking, team-work spirit and language expression ability. As mentioned above, teachers should put a high value on cultivating the students' ability of finding problems, analyzing problems and solve problems. Teachers need to be aware of the value of PBL teaching model in cultivating students' deep learning.

This is the application of PBL in primary schools. In addition, three points should be noted in higher education in the application of PBL. 


\section{PBL TEACHING PATTERN USAGE IN THE HIGHER EDUCATION}

\subsection{The Application of PBL in Higher education is combined with the teaching purpose.}

Grossman et al. point out that the PBL is suitable for all students, but a single teaching practice is not ideal for all times [12]. During the application of PBL, students are centered, and teachers play the role of assistants. It means that PBL encourages students to explore knowledge independently under the knowledge which they have learned. However, students who have just started to contact professional courses have little specific professional knowledge. Therefore, students' independent explorations and deep research must be conducted after learning some professional knowledge. Similarly, in higher education, due to the lack of teaching experience or the lack of students' information, new teachers may fail to timely or accurately reflect students' problems in applying the PBL teaching method, which makes the PBL teaching method ineffective and unsatisfactory. Therefore, if teachers do not have enough preparations in mastering PBL, they might not be able to utilize PBL well in their courses under great pressures. In that case, it may lead to tremendous pressure on teachers and is likely to let students fall into a state of confusion and loss of enthusiasm, cause harm to the physical and mental health of teachers and students, the teaching plan time off schedule.

\subsection{Encourage Students Appropriately in PBL}

PBL has advantages in the development of problem solving and teamwork. Simone et al. 's experiment pointed out that the PBL method in computer education promotes students' team participation and learning ability, contributes to good practices, and trains students with a holistic vision [13]. In the group discussion, the interaction between different members is conducive for students to exchange extra information and the vigorous development of other ideas, even helps students think about problems in various aspects from different perspectives, which is conducive to students thinking about issues from different perspectives and facets. Hence, to improve the participation of students, teachers should give some encouragement when guiding students to discuss. Almulla points out that students and teachers can benefit from PBL through professional and emotional support [14]. It indicates that appropriate encouragement can promote the implementation of the PBL teaching method. As a facilitator, the teacher can give proper positive feedback to the students when listening to the group discussion and provide an appropriate affirmation to the students when they show their achievements. The teacher's commitment to the mutual responsibility between students can enhance students' self-confidences and sense of accomplishments, further improves students' enthusiasm for communication and information interaction, increases the diversity of group discussion results, and promotes the development of the shared world.

\subsection{The Sustainability of $P B L$}

One of PBL's principles is to create a connection to Society. Noordegraaf-Eelens et al. argues that within this principle's scope, making sustainable development of PBL, is essential to shared world responsibility, and it cannot happen without any action [15]. Action is crucial in education. Voice finds that connecting these different strands, we define action as articulating the world and creating it anew within the context of education [16]. PBL provides students with the opportunity to explore the world on their own in two ways: independent exploration and group work. Independent exploration requires students to think independently by querying materials or doing experiments after group division; Group cooperation requires students to share information based on the knowledge they have queried or learned, both of which cannot be separated from students' actions. Students continue to learn through the PBL learning method, complete information exchange through active group discussion, internalize known information into knowledge through group discussion, and use knowledge as information exchange. Through this continuous cycle of action, students can overthrow the known world and build a new world by constantly learning new knowledge to realize the sustainable development of knowledge, which promotes the implementation of the PBL teaching method from the inside, and further supports the sustainable developments of PBL.

\section{CONCLUSION}

Nowadays, PBL teaching mode has gradually comes into people's view. Starting with the analysis of its theoretical basis and combining with some empirical studies, the researcher compares the traditional teaching mode with PBL teaching mode, puts forward the constitutive elements of this mode, the implementation process and some key points to pay attention to, and evaluate of this kind of mode. PBL teaching mode is widely used because of its rich theoretical basis among pre-school education, primary and secondary schools and higher education stage. Its education content and teaching mode reasonable grafting, explore and update the various stages of the teaching methods in education, will better promote the sustainable development of the students, and teacher's professional developments. PBL is a novice type of teaching model, which puts students' learning in real problem situations. It encourages students to think positively and adopt suitable learning methods to solve problems and share results to achieve learning goals. Teachers adopt the PBL teaching method to give students 
the initiative in learning, assign teaching tasks, improve students' ability to solve practical problems, and acquire relevant knowledge and stimulate students' interest in learning. This study aims to provide new ideas for educational reform by summarizing the application status of the PBL teaching model in different levels of education. We conducted an extended analysis of the application of PBL in preschool education, primary education, and higher education, compared the PBL teaching method with the traditional teaching method, and understood the different performance of students of different ages and their emphasis on learning content. PBL teaching mode has been involved and applied in various levels of learning. We believe that it will have a broader application prospect and more obvious teaching effects after continuous improvement.

\section{REFERENCES}

[1] Lu, Q., Liang, H., Chen, S., \& Zhou, Q. (2019). Problem Based learning (PBL) model and its strategies for promoting children's independent inquiry. Education Guide (Second Half) (02),14-18. doi:CNKI:SUN: YJye-0.2019-02-003.

[2] Tang X.H., Chen X.Y. \& Hu J. M. (2018). The impact of project learning (PBL) on early childhood education. Xizang Science and Technology (03),3739. doi:CNKI:SUN: xZkJ.0.2018-03-013.

[3] Paulo A. C. (2018). Teaching lean manufacturing at a postgraduate level. International Journal of Lean Six Sigma, 9(3), 301-323.

[4] Chi, L. P. (2009). Problem-based learning: an effective way to achieve the goal of preschool Children's quality education. Preschool Curriculum Research (02),8-11. XqKC.0.2009-02-004.

[5] Warnock, J. N., \& Mohammadi-Aragh, M. J. (2016). Case study: use of problem-based learning to develop students' technical and professional skills. European Journal of Engineering Education, 41(2), 142-153.

[6] Blichfeldt \& Smed. (2020).PBL in today's mass university: incrementalism as a coping strategy for students. Journal of Further and Higher Education (6), doi:10.1080/0309877X.2019.1627297.

[7] Wei. S. (2019). Based on PBL teaching pattern, the practice of primary school morality and social studies(03),101-102.doi:CNKI:SUN:JYJT.0.201903-058.

[8] Zejnilagić-Hajrić, M., Šabeta, A., \& Nuić, I. (2015). The effects of problem-based learning on students' achievements in primary school chemistry. Bulletin of the Chemists and Technologists of Bosnia and Herzegovina, 44, 17-22.

[9] Palupi, B. S., \& Subiyantoro, S. (2020). The Effectiveness of Guided Inquiry Learning (GIL) and Problem-Based Learning (PBL) for Explanatory Writing Skill. International Journal of Instruction, 13(1), 713-730.

[10] Odell, M. R., Kennedy, T. J., \& Stocks, E. (2019). The impact of PBL as a STEM school reform model. Interdisciplinary Journal of Problem-Based Learning, 13(2), 4.

[11] Aksela, M., \& Haatainen, O. (2019). Project-Based Learning (PBL) in Practise: Active Teachers' Views of Its' Advantages And Challenges. In Integrated Education for the Real World 5th International STEM in Education Conference Post-Conference Proceedings. Queensland University of Technology.

[12] Grossman, P., Dean, C. G. P., Kavanagh, S. S., \& Herrmann, Z. (2019). Preparing teachers for projectbased teaching. Phi Delta Kappan, 100(7), 43-48.

[13] Tolga E. \& Nuray S.PBL in teacher education: its effects on achievement and self-regulation[J]. Higher Education Research\& Development, 2017(64):233-244.

[14] dos Santos, S. C., Reis, P. B., Reis, J. F., \& Tavares, F. (2020). Two Decades of PBL in Teaching Computing: A Systematic Mapping Study. IEEE Transactions on Education.

[15] Noordegraaf-Eelens, L., Kloeg, J. \& Noordzij, G. PBL and sustainable education: addressing the problem of isolation. Adv in Health Sci Educ 24, 971-979 (2019).

[16] Voice, P. (2014). Labour, work and action. In P. Hayden (Ed.), Hannah Arendt: Key concepts (pp. 36-51). London and New York: Routeledge. 